\title{
Unequal age-based household emission and its monthly variation embodied in energy consumption-A cases study of Tokyo, Japan ${ }^{1}$
}

\author{
Yin Long a , Yoshikuni Yoshidaa ${ }^{\mathrm{a}}$, Jing Meng ${ }^{\mathrm{b}}$, Dabo Guan ${ }^{\mathrm{c}}$, Liming Yao ${ }^{\mathrm{d}}$, Haoran Zhang ${ }^{\mathrm{e}}$ \\ ${ }^{a}$ Department of Environment System, Graduate School of Frontier Sciences, The University of Tokyo, 5-1- \\ 5 Kashiwanoha, Kashiwa, Chiba 277-8563, Japan \\ ${ }^{b}$ The Bartlett School of Construction and Project Management, University of College London, London \\ WCIE $7 H B, U K$ \\ ${ }^{c}$ Water Security Research Centre, School of International Development, University of East Anglia, Norwich, \\ NR4 7TJ, UK \\ ${ }^{d}$ Business School, Sichuan University, Chengdu, 610000, China \\ ${ }^{e}$ Center for Spatial Information Science, The University of Tokyo 5-1-5 Kashiwanoha, Kashiwa-shi, Chiba, \\ 277-8568, Japan
}

\begin{abstract}
City is the main place to consume goods and services throughout the world. Among the various consumption terminals, household-level consumption is highly behavior driven, which can be affected by various factors such as household income level, age, living environment etc. However, city-level household emissions characteristics are still not fully understood due to the complexity of consumption behaviors and the lack of the supply chain's data. To include the environmental responsibility embodied in residential consumption and reveal the how it varies among household type and season, this study investigated city-level household consumption as it relates to energy demand using a cityscale input-output model and urban residential consumption inventories. Importantly, age- and monthbased emission are analyzed from different aspects such as emission type, source, fuel types and consumption items. Findings indicate that 1 ) household emissions differ substantially among the various household age groups; older households generally produce higher emissions levels on a per
\end{abstract}

1 The short version of the paper was presented at CUE2018, Jun 5-7, Shanghai, China. This paper is a substantial extension of the short version of the conference paper. 
capita basis; 2) decreases in temperature are the main reason for the increased emissions in older households, while this is not a significant factor in younger households; 3) the high per capita household emissions in older households indicate inefficient energy usage among elder citizens, which strongly suggests that aging societies will face long-term emissions increases if appropriate measures are not taken.

Keywords: Household embodied consumption; Unequal emission, Ten age-based groups; Monthly emission; City-level input-output model.

\section{Introduction}

Cities have become the predominant habitat of humans. City dwellers now account for over half the world's population (Chen, Hadjikakou, \& Wiedmann, 2017). As a consequence, cities face the unprecedented task of balancing environmental and economic benefits. Today, the majority share of energy consumption and emissions occurs within cities or is related to ongoing urbanization (Joji, Miura, \& Yutaka, 1999; Long, Dong, Yoshida, \& Li, 2018; Long \& Yoshida, 2018; Singh \& Kennedy, 2015). In this circumstance, the transformation of the upstream structure of the energy supply chain (H. Zhang, Liang, Liao, Wu, \& Yan, 2017; H. Zhang, Y. Liang, Q. Liao, X. Yan, et al., 2017) and the in-boundary/trans-boundary allocation of $\mathrm{CO}_{2}$ emissions present major challenges. To capture cityscale energy consumption and emissions, CBA (Consumption-based Accounting) provides a consumer-oriented insight to emphasize the major role of consumption behavior. By applying CBA, the question of how best to assign sub-national emissions responsibility and enabling policymakers to track the urban environmental impact from upstream to downstream can be adequately addressed.

As the role of consumers has become increasingly important, CBA has been widely employed, under the concept of environmental "footprint" derived from Life Cycle Assessment. It is clear that the demand side of an economy affects $\mathrm{CO}_{2}$ emissions in the production sector via consumption behaviors and directly or indirectly influences the use of resources as well as the release of emissions. As to make CBA possible, economic input-output tables have been converted into environmentally extended versions in order to capture inter-industrial or interregional environmental impact transfers (Ramaswami, Chavez, Ewing-Thiel, \& Reeve, 2011). Here, EEIO (Environmental Extended Input- 
Output analysis) provides technological support to solve the emissions quantification problem using complex inter-industrial correlations. When applied to city-scale emissions accounting, a down-scaled I-O (Input-Output) table is preferable; however, this is usually unavailable in many national or smaller scale cases. In this study, we use a city-scale input-output table to capture the embodied emission by source and sector. In so doing, consumption-based accounting on a city-scale is then possible and down-scale emissions insights can provide an appropriate basis to support effective environmental policymaking regarding future allocations.

Of the many components of a city system, households rank among the biggest consumers of energy and goods of all types. Indeed, according to EEIO analysis conducted in previous studies, household consumption is the largest contributor to overall energy usage; it follows, then, that households are responsible for a majority of related emissions (Büchs \& Schnepf, 2013; Perobelli, Faria, \& Vale, 2015; Y.-J. Zhang, Bian, Tan, \& Song, 2015). Such as Wiedenhofer et al. (2016) show that residential carbon emissions are unequally distributed among rich and poor households in China (Wiedenhofer et al., 2017). Moreover, it has been suggested that the heterogeneity of household income levels may lead to unequal household energy consumption and associated emissions (J. Zhang, Yu, Cai, \& Wei, 2017). In Japan, household consumption accounts for more than half of overall emissions and can be seen as a major contributor after breaking down the carbon footprint by final demand (Long, Yoshida, Zhang, Sun, \& Dou, 2018; Nansai et al., 2012). Consumption habits at the household-level are highly behavior-driven, suggesting that an understanding of household consumption patterns can produce environmental benefits (Froemelt, Dürrenmatt, \& Hellweg, 2018). Accordingly, analyses of household consumption and its corresponding environmental impact have proliferated in recent years, focused not just on the evaluation of household direct and indirect emissions (Büchs \& Schnepf, 2013; Long, Yoshida, \& Dong, 2017; Reinders, Vringer, \& Blok, 2003; Zhu, Peng, \& Wu, 2012), but also on the driving forces (Y. Shigetomi, Nansai, Kagawa, \& Tohno, 2014; Wang, Liu, \& Yin, 2014) as well as the potential impact factors (such as lifestyle) (Froemelt et al., 2018; H. Zhang et al., 2018). Shigetomi et al. (2014) present a breakdown of GHG emissions from Japanese household consumption by consumption expenditure sectors from 2005 to 2035 and provide insights into the effectiveness of targeting middle-aged and older households to achieve emissions reduction targets through technological improvements in household commodities (Y. Shigetomi et al., 2014). Shigetomi et al. (2018) also demonstrate how household size impacts overall emissions, pointing out that recent regional $\mathrm{CO}_{2}$ emissions increases are significantly correlated with recent demographic trends (Yosuke Shigetomi et al., 2018). Japan is now facing many demographic issues such as aging, low birthrate, 
ratio change of working population, household dilution etc. It's important to reveal the household emission by considering household age, since the commonness by age can give a clue for customizing residential energy polices. On the other hand, household consumption is highly behavior-driven, which indicate the energy consumption not just varies by household feature, but also by the climatic condition such as temperature. Therefore, this study is trying to reveal the unequal emission generated by different household group and analyze its seasonality. The result will provide vital clue to customize low-carbon household polices by considering the feature of household age and seasonality.

Residential emission reduction is one important pillar to overcome Japan's energy challenges and realize a stable energy mix. As an important commitment to Paris Agreement, Japan's INDCs indicates $26 \%$ of greenhouse gas emission is expected to reduce by fiscal year 2030 based on the emission level of fiscal year 2013. However, a restructuring of Japan's energy society is happening since Great East Earthquake of 2011. Following the earthquake and the post-earthquake disasters, reformulation of climate policy largely impacts on the Japan henceforth. Along with the risk of energy security and climate security, the current situation also provides a Japan a new start line for completing the policy making process.

Nevertheless, there appear to be no studies that examine Japan's urban household carbon emissions with a focus on the seasonal carbon emission and household age groups, that may impact on household energy consumption to a large extend. Moreover, to our knowledge, only a few studies of intra-annual emissions variations using a top-down assessment method such as EEIO have been conducted. We aim to bridge the gap by investigating city-scale monthly carbon emissions using a consumption-based accounting method and analyzing monthly household emissions variations. Three major fossil fuels are included in the study: coal, crude oil, and natural gas. Both direct and indirect household emissions - that is, emissions resulting from responses to household energy needs - are calculated; emissions categories and the fuel structure of Tokyo city are also included, providing a solid basis for the formulation and implementation of low carbon policy in the residential sector. In this study, a comprehensive analysis is provided by applying input-output data with consumption inventory data. The findings are discussed from the inequality among household age-based groups. This unequal emission is discussed by month so the emission seasonality can also be considered. The results are discussed from the flowing aspects: emission source (Domestic or leaked emission), fuel type (Coal, Crude Oil and Natural gas), emission type (Direct or indirect) and consumption items. 


\section{Methodology}

\subsection{Study area}

In recent decades, cities have taken on a leadership role in GHG (Greenhouse Gases) mitigation and related policy implementation. The challenge of cities, especially mega cites, lies in striking the proper balance between economic performance and environmentally sustainable development. City-scale research is central to the ability of cities to make a significant contribution to GHG reduction and assert their leadership on environmental issues. Tokyo, the centre of Japan both economically and politically, is one of great mega cities of the world. It covers an area of $2088 \mathrm{~km}^{2}$. In 2011, Tokyo was home to 6324 thousands of households; a majority of its population is highly concentrated in its 23 wards. Fig. 1 shows the location of Tokyo city, which includes the Tama-area and the 23 wards. Although the jurisdiction of Tokyo includes several remote islands such as Izu Island and Ogasawara Island, most of its residents are concentrated in the city's 23 wards and the Tama area. Due to its size and its potential contribution to city-level low carbon policy implementation, Tokyo has greatly adjusted its energy structure in order to accelerate the application of ambitious low-carbon measures. Illustrative of its efforts, in December 2006, TMG (Tokyo Metropolitan Government) announced its goal of reducing GHG emissions by 25\% by FY2020 (Fiscal Year 2020) relative to the city's FY2000 level. To this end, specific policy directions were delineated in the Tokyo Climate Change Strategy and the Tokyo Metropolitan Environmental Master Plan. Such measures demonstrate the commitment of Tokyo to formulating a robust, long-term sustainable energy policy. Recognizing the significant impact on city-level emissions reduction research that would result, this study chose Tokyo as its case city.

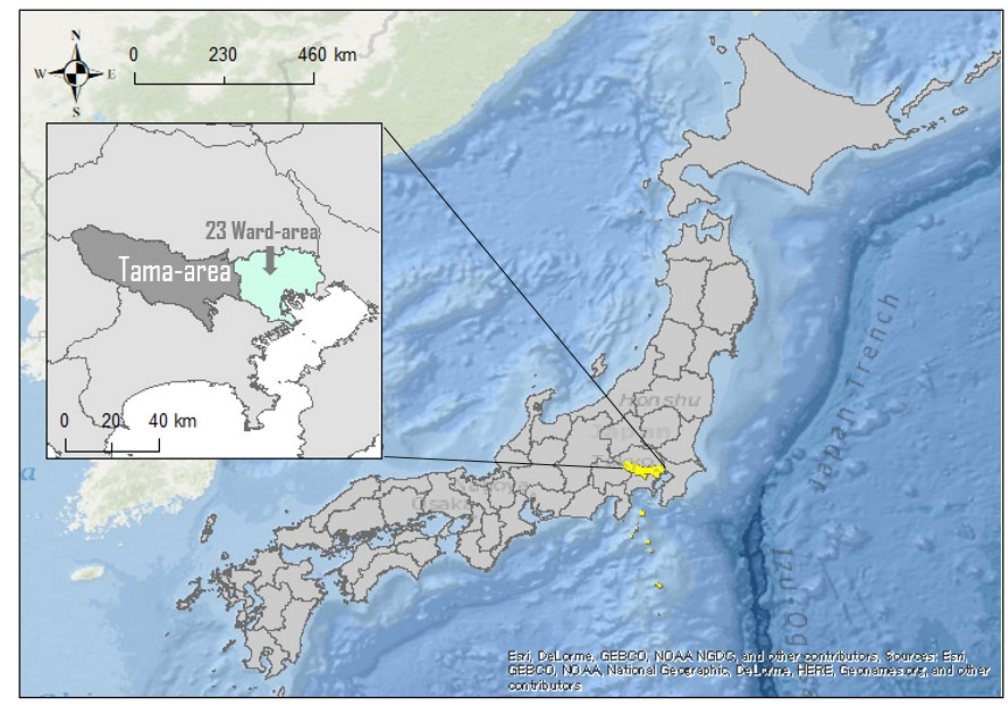

Fig. 1. Geographic location of study area. 


\subsection{System boundary and analytical framework}

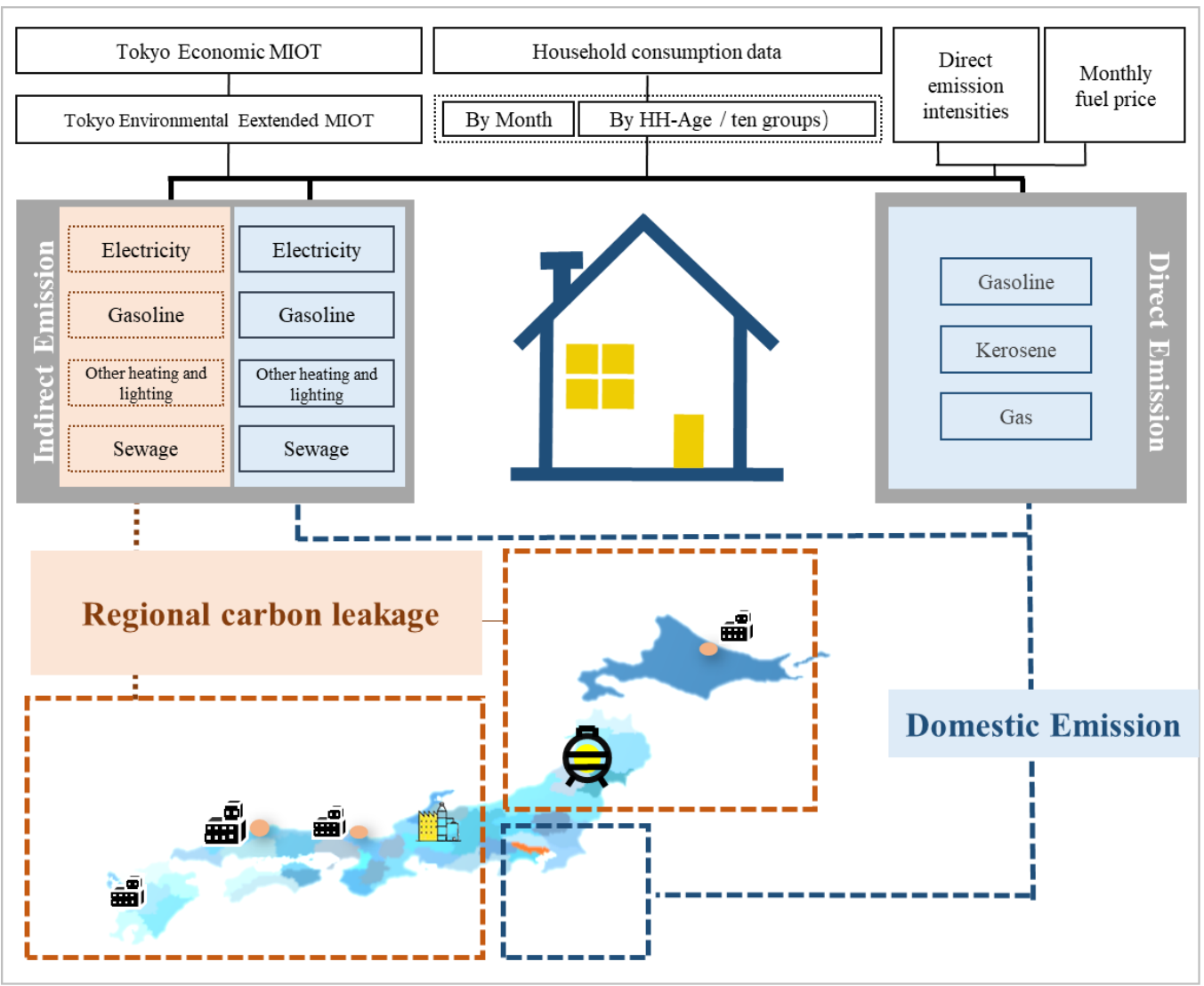

Fig. 2. System boundary and flowchart of this study.

Fig. 2 shows the system boundary and analytical framework of the study. Age-based household consumption data are derived from the Tokyo 2011 monthly household consumption inventory, which we sort into ten groups according to head-of-household age. Since the focus of this study is on energy-related consumption, gasoline, natural gas, electricity, kerosene, sewage and other heating and lighting categories are selected. Some of the listed fuels, including gasoline, natural gas and kerosene, are burned directly by the household, while others are consumed indirectly, being burned in the production process, as in the case of electricity. Gasoline generates emissions both directly and indirectly, which is accounted for in our calculations. On the one hand, the direct emissions of these various energy types are comparatively simple to evaluate. However, determining the indirect emissions of Tokyo households requires indirect emission intensities generated by considering the embodied emissions released in other sectors. In this case, not only is the inter-industrial correlation inside Tokyo necessary; the calculation of cross-boundary energy flow is 
also required. To make the indirect emissions calculations, an economic multi-regional input-output table (MIOT) is applied and further extended into EEIO. In this way, the indirect emissions can be sourced both inside and outside of Tokyo. By combining this with the household consumption inventory mentioned previously, monthly carbon emission is computable for each of the ten defined household groups. The aim of this study is to quantify monthly city-level emissions responsibility considering the embodied part. Results can be further interpreted to explain how aging affects household energy efficiency seasonally.

\subsection{Direct emissions from residential energy consumption}

Direct carbon emissions generated from household consumption are those associated with fuels burned for daily household energy demand. Considering the general consumption habits of the study area, the study included three different fuel types: natural gas, gasoline and kerosene. These fuels are consumed by Tokyo's residential sector for cooking, showering, driving, heating, and lighting. Notably, although kerosene is not commonly used in highly urbanized areas, it is used to a limited degree in places such as the Tama-areas in the west of Tokyo. Data on Tokyo household expenditures in 2011 were used here to discern the consumption patterns of the ten household groups sorted by head-of-household age. All data are driven from the Tokyo Statistics Bureau and at monthly resolution. Direct carbon emissions generated from household consumption are those associated with fuels burned for daily household energy demand. Considering the general consumption habits of the study area, the study included three different fuel types: natural gas, gasoline and kerosene. These fuels are consumed by Tokyo's residential sector for cooking, showering, driving, heating, and lighting. Notably, although kerosene is not commonly used in highly urbanized areas, it is used to a limited degree in places such as the Tama-areas in the west of Tokyo. Data on Tokyo household expenditures in 2011 were used here to discern the consumption patterns of the ten household groups sorted by head-of-household age. All data are taken from the Tokyo Statistics Bureau at monthly resolution. There are 10000 households selected by each month randomly to conduct this survey. The detail of this survey is shown as Table 1.

Table 1. Percentage of age-based household groups in the expenditure survey by month (\%).

\begin{tabular}{ccccccccccccc}
\hline & Jan & Feb & Mar & Apr & May & Jun & Jul & Aug & Sep & Oct & Nov & Dec \\
\hline$<30$ & 1.47 & 1.3 & 0.95 & 1.4 & 2.02 & 1.93 & 2 & 2.13 & 2.34 & 2.35 & 1.84 & 2.59 \\
$\mathbf{3 0 ~} \mathbf{3 4}$ & 4.69 & 4.17 & 4.43 & 3.66 & 3.07 & 3.75 & 3.04 & 3.1 & 3.2 & 3.3 & 3.33 & 3.71
\end{tabular}




\begin{tabular}{cccccccccccccc}
$\mathbf{3 5} \sim \mathbf{3 9}$ & 8.03 & 9.06 & 8.53 & 9.05 & 9.09 & 9.4 & 9.78 & 8.3 & 9.27 & 9.3 & 8.6 & 7.95 \\
$\mathbf{4 0} \sim \mathbf{4 4}$ & 11.32 & 12 & 12.73 & 11.98 & 11.51 & 10.35 & 9.97 & 9.61 & 9.68 & 9.14 & 8.68 & 9.72 \\
$\mathbf{4 5} \sim \mathbf{4 9}$ & 10.74 & 10.23 & 10.98 & 10.11 & 10.23 & 10.88 & 11.94 & 12.73 & 12.67 & 12.4 & 12.6 & 11.23 \\
$\mathbf{5 0} \sim \mathbf{5 4}$ & 8.69 & 7.83 & 7.38 & 7.51 & 7.68 & 8.08 & 9.79 & 9.27 & 8.74 & 8.94 & 8.96 & 7.97 \\
$\mathbf{5 5} \sim \mathbf{5 9}$ & 9.16 & 9.16 & 8.73 & 8.12 & 8.25 & 9.34 & 8.59 & 9.25 & 9.61 & 9.3 & 9.29 & 8.9 \\
& & & & & & & & & & & & \\
$\mathbf{6 0} \sim \mathbf{6 4}$ & 13.16 & 13.16 & 11.75 & 12.95 & 14.01 & 13.03 & 11.08 & 11.45 & 11.57 & 11.43 & 11.44 & 11.55 \\
$\mathbf{6 5} \sim \mathbf{6 9}$ & 10.72 & 9.94 & 9.29 & 9.27 & 8.96 & 9.38 & 9.61 & 10.68 & 10.38 & 10.57 & 10.74 & 11.07 \\
$\mathbf{7 0 <}$ & 22.02 & 23.15 & 25.24 & 25.94 & 25.17 & 23.86 & 24.19 & 23.48 & 22.52 & 23.27 & 24.52 & 25.32 \\
\hline
\end{tabular}

Then, we converted monetary consumption into energy consumption by applying monthly energy retail prices, emission intensities, and calorific values provided by the Agency for Natural Resources and Energy in Japan. The direct emissions of urban households could be expressed as

$$
R E_{\text {direct }}=\sum \sum \sum C_{i}^{t} * P_{i, j} * \operatorname{Cal}_{i} * E t_{i}
$$

where $C_{i}^{t}$ indicates residential monetary expenditure on fuel type $i$ by household type $t$. As mentioned, we divided the households into ten groups according to head-of-household age (HH-Age). Table 2 shows the groups that were formed. Grouping households enables us to determine typical household emissions characteristics and to examine whether fluctuations in household emissions are related to household demographic features. $P_{i, j}$ is the energy price of fuel type $i$ in month $j$. Therefore, $C_{i}^{t} * P_{i, j}$ refers to direct residential energy consumption of fuel type $i$ in month $j$ by household type $t . \mathrm{Cal}_{i}$ and $E t_{i}$ represent, respectively, the caloric value and emission intensity of fuel type $i . R E_{\text {direct }}$ is thus the total residential emissions across the year resulting from the burning of all three fuel types.

Table 2. Household grouping by head-of-household age (HH-Age).

\begin{tabular}{cccc}
\hline No. & HH-Age (yrs.) & No. & HH-Age (yrs.) \\
\hline H-1 & $<30$ & H-6 & $50 \sim 54$ \\
H-2 & $30 \sim 34$ & H-7 & $55 \sim 59$ \\
\hline
\end{tabular}




\begin{tabular}{lccc}
\hline H-3 & $35 \sim 39$ & H-8 & $60 \sim 64$ \\
H-4 & $40 \sim 44$ & H-9 & $65 \sim 69$ \\
H-5 & $45 \sim 49$ & H-10 & $>69$ \\
\hline
\end{tabular}

\subsection{Indirect emissions from residential energy consumption}

Of course, household energy consumption generated directly by the burning of fuels only partially represents total household energy consumption. Electricity, for example, sustains the daily functioning of urban dwellers, yet no direct emissions are generated in its final use. However, the process of producing electricity from primary energy sources causes substantial energy consumption and generates major amounts of carbon emissions. Considering that emissions are generated across the full supply chain of energy products, these emissions should be accounted for in final usage since all up-stream input and production is triggered by the needs of final consumption. Such a conclusion is in full accordance with consumption-based accounting. The input-output model adopted here represents the economic interdependencies among the various sectors of an economy, allowing us to dig out the deep-seated stickiness among industries and economies. By applying such an input-output model, inter-industrial energy consumption can be calculated from the consumption side and emissions responsibility can be quantified from the demand side. The method applied here uses the Leontief Inverse Matrix to solve a set of matrix equations, enabling us to capture the economic transactions embodied in intermediate goods and services. Previous studies have indicated that the strength of this method is its ability to provide complete and systematic coverage of the entire upstream supply chain (Manfred Lenzen, 1998; Manfred Lenzen, Murray, Korte, \& Dey, 2003; Manfred Lenzen, Pade, \& Munksgaard, 2010; M. Lenzen et al., 2006; Manfred Lenzen, Wood, \& Wiedmann, 2010). As for its suitability in studies regarding indirect effects, IOA (Input-output Analysis) has been extended, to good effect, to environmental IOA as a way to capture indirect environmental impacts. However, inter-regional commodities transfer complicate attempts to evaluate total regional environmental impact, especially in highly urbanized regions. To address this problem, multi-regional, environmentally extended input-output analysis (EEIO) has been used to incorporate differences in production technologies among regions (Mach, Weinzettel, \& Ščasný, 2018). Multi-regional EEIO can reflect the environmental effects of changes in final demand and also reveal the effects of one industry on another by regions. When EEIO is used in the assessment of residential emissions, the competitive import-type model can be expressed as 


$$
X=[I-(I-\widehat{M}) A]^{-1}[(I-\widehat{M}) F+\text { Export }]
$$

where $X$ is domestic output, in Japanese Yen (JPY), for one year; $[I-(I-\widehat{M}) A]^{-1}$ indicates the Leontief competitive import-type inverse matrix; and $I$ is the unit matrix. $\widehat{M}$ indicates the diagonal matrix relating to the import index, and $F$ is the diagonal matrix to convert the column vector based on final demand from the input-output table (consumption scale). $A$ indicates the complete demand coefficients matrix reflecting changes in intermediate demand from the various industries. Indirect carbon emissions can then be calculated by applying the following equation:

$$
E_{\text {indirect }}=E * B[(I-\widehat{M}) F+\text { Export }]
$$

where $E_{\text {indirect }}$ indicates the indirect carbon emissions embodied in final demand, including exports; $E$ is the row vector of direct carbon intensities (direct carbon emissions per unit of gross output) generated from the economic input-output table; and $B$ is $[I-(I-\widehat{M}) A]^{-1} . E B$ thus indicates the indirect emission intensities that take into account inter-industrial energy transfers. In this study, we define as carbon leakage indirect emissions generated by other regions based on Tokyo's demand. The emissions embodied in Tokyo final demand can, therefore, be divided into domestically generated emissions and leaked emissions:

$$
\begin{gathered}
{[I-(I-\widehat{M}) A]^{-1}=\left[\begin{array}{cc}
t t B & t o B \\
o t B & o o B
\end{array}\right]} \\
\text { DomesticR } E_{\text {indirect }}=C * E *(t t B+\text { ot } B) \\
\text { LeakedRE } E_{\text {indirect }}=C * E *(t o B+o o B) \\
R E_{\text {indirect }}=\text { LeakedRE } E_{\text {indirect }}+\text { DomesticR } E_{\text {indirect }}
\end{gathered}
$$

where $t t B, t o B$, ot $B$, and $o o B$ are generated based on the input-output table indicating, respectively, Tokyo input to Tokyo output ( $t t)$, Tokyo input to other-region output (to), other-region input to Tokyo output (ot), and other-region input to other-region output (oo). Tokyo residential indirect emissions include emissions embodied in Tokyo final consumption from domestic production as well as production in other regions. $E *(t o B+o o B)$, then, refers to leaked emission intensities.

The emission intensities generated from the input-output table $\left(E_{f}\right)$ can be further divided according to type of fuel-coal $\left(E_{\text {coal }}\right)$, crude oil $\left(E_{\text {oil }}\right)$, and natural gas $\left(E_{\text {gas }}\right)$. Thus, the monthly indirect emissions embodied in Tokyo energy consumption can be calculated as

$$
R E_{\text {indirect }}=\sum \sum \sum C_{i}^{t} * E_{f} *(t t B+o t B)+\sum \sum \sum C_{i}^{t} * E_{f} *(t o B+o o B)
$$


Finally, total Tokyo residential emissions, $R E$, can be shown as

$$
R E=R E_{\text {direct }}+R E_{\text {indirect }}
$$

where $R E$ indicates total household emissions and includes both direct energy combustion and the indirect energy generation process. In this way, household energy-related emissions can be calculated from both fuels burned directly and from the upstream supply chain.

The most recent Tokyo input-output table, the table for 2011 , is used in this study to capture the entire emissions situation of the upstream supply chain. It has been pointed out that urban households consume substantial energy either directly or indirectly and are therefore responsible for the majority of anthropogenic greenhouse gas emissions. The method described above, combined with available household consumption data, can be used to determine city-scale residential emissions by month, by household group, by emission type (direct and indirect), by fuel type (coal, crude oil, natural gas), and by household energy category, as well as identify the general location of the emissions (within or outside the city boundary).

\section{Results and discussion}

Household monthly energy consumption closely relates to the climatic condition. Before discussing calculation result, climatic condition of study area is shown as Table 3., which is driven from Japan Meteorological Agency. From the Table 3., the lowest temperature is found to be January, and the highest temperature is found to be August. The temperature can impact household energy consumption from different aspects, such as heating, showing or even can decide the in-house time of household members.

Table 3. Climatic condition of study area (Jan.2011 to Dec.2011)

\begin{tabular}{|c|c|c|c|c|c|c|c|c|c|}
\hline \multirow{3}{*}{ Month } & \multicolumn{4}{|c|}{ Precipitation (mm) } & \multicolumn{5}{|c|}{ Temperature $\left({ }^{\circ} \mathrm{C}\right)$} \\
\hline & \multirow[b]{2}{*}{ SUM } & \multicolumn{3}{|c|}{ MAXIMUM } & \multicolumn{3}{|c|}{ AVERAGE } & \multirow[b]{2}{*}{ Highest } & \multirow[b]{2}{*}{ Lowest } \\
\hline & & Day & Hour & $\begin{array}{c}10 \\
\text { minutes }\end{array}$ & $\begin{array}{c}\text { Day } \\
\text { average }\end{array}$ & $\begin{array}{c}\text { Daily } \\
\text { maximum }\end{array}$ & $\begin{array}{c}\text { Daily } \\
\text { minimum }\end{array}$ & & \\
\hline Jan & 3.5 & 3.5 & 2 & 1 & 5.1 & 9.1 & 1.5 & 12.2 & -1.1 \\
\hline Feb & 151 & 76.5 & 17 & 4 & 7 & 11.2 & 3.2 & 20.8 & -0.8 \\
\hline Mar & 74 & 28 & 6 & 1.5 & 8.1 & 12.3 & 4 & 20.2 & 1 \\
\hline Apr & 96 & 54 & 12.5 & 6 & 14.5 & 18.9 & 10.3 & 24.8 & 4.3 \\
\hline May & 213.5 & 69.5 & 12.5 & 5 & 18.5 & 22.2 & 15 & 29.6 & 12.2 \\
\hline Jun & 116.5 & 35.5 & 13 & 3 & 22.8 & 26 & 19.9 & 35.1 & 12.1 \\
\hline
\end{tabular}




\begin{tabular}{rrrrrrrrrr}
\hline Jul & 54.5 & 29 & 18.5 & 8.5 & 27.3 & 30.9 & 24.5 & 34.8 & 18 \\
Aug & 244 & 88.5 & 55 & 16.5 & 27.5 & 31.2 & 24.6 & 36.1 & 19.3 \\
Sep & 235 & 124 & 28 & 11.5 & 25.1 & 28.8 & 22 & 32.5 & 15.9 \\
Oct & 119.5 & 53.5 & 11 & 5 & 19.5 & 23 & 16.5 & 29.7 & 11.2 \\
Nov & 112.5 & 78 & 12 & 3 & 14.9 & 18.3 & 11.7 & 22.7 & 7.2 \\
Dec & 59.5 & 35 & 7.5 & 2 & 7.5 & 11.1 & 4.2 & 18.9 & 1.5 \\
\hline
\end{tabular}

\subsection{Total monthly total carbon emissions by age-based household type}

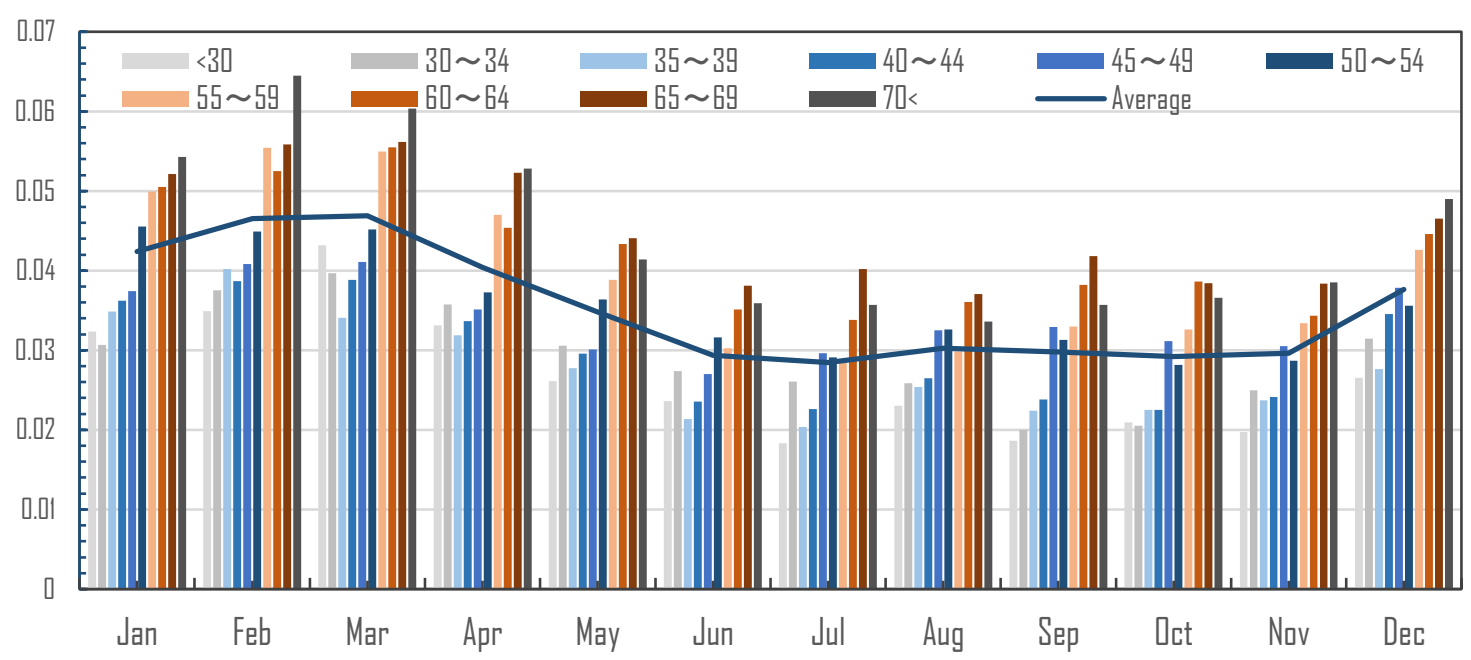

Fig. 3. Total monthly emissions by age-based household type (Unit: tC per capita).

Although the actual structure of household energy consumption and the behavior of residential emissions are difficult to establish due to their complexity, it is nevertheless essential that we be able to determine both. Detailed emissions information that can be generated when emissions are classified into specific categories, such as fuel type, emissions source, and consumption item, serves multiple purposes. For example, knowledge of fuel-specific emissions contributes to our understanding of the residential household energy supply chain and has the potential to play a role in its optimization; source-specific emissions information can clarify the regional emissions responsibility of each economic agent; and household-demand-specific information is essential to devising measures that will promote environmentally-friendly consumption behaviors. Based on our methodology, we are able to establish city-scale emissions fluctuations by emissions source in an effort to determine regional emissions responsibility. Our approach measures household-group-specific monthly energy- 
related emissions for Tokyo in 2011 based on our input-output model; results can be further broken down by fuel type, emissions source, emissions type, and consumption item.

Fig. 3 shows the month-by-month emissions distribution for each of the ten age-based household types. Total emissions include emissions produced within the city of Tokyo as well as the embodied emissions leaked to other regions. From the figure, it appears that a comparatively high emissions level is maintained from February to March, after which time the emissions level gradually decreases. The emissions gap among the household groups also changes substantially from month to month, suggesting that household energy consumption is impacted by different seasonal switching behaviors on the part of the various household groups.

\subsection{Monthly domestic and leaked carbon emissions for ten HH-age-based household types}

When production takes place beyond a particular region or district border, the impacts embodied in and associated with the resulting commodity exchanges brings about a displacement of environmental burden. Carbon leakage occurs in such regional exchanges. In this study, we subdivide embodied household consumption into two parts based on where production takes place. Fig. 4 shows the monthby-month domestic and leaked emissions of all household groups in which the head-of-household is under 50 years of age (H-1 to H-5). In each case, several peaks are evident over the subject one-year period. The maximum emissions of all the household groups represented in Fig. 4 occur during the months of January, February and March, when most days in Japan are characterized by relatively low temperatures. However, as household age increases, days with relatively high temperatures, particularly in August and September also show high emissions levels. The high emissions levels of group H-5 in February and September are noteworthy. Although a high percentage of the carbon emissions are generated within the Tokyo city boundary, leaked emissions - emissions produced outside Tokyo - contribute substantially to the household emissions total. Moreover, the leaked carbon level increases as the head-of-household age increases. 

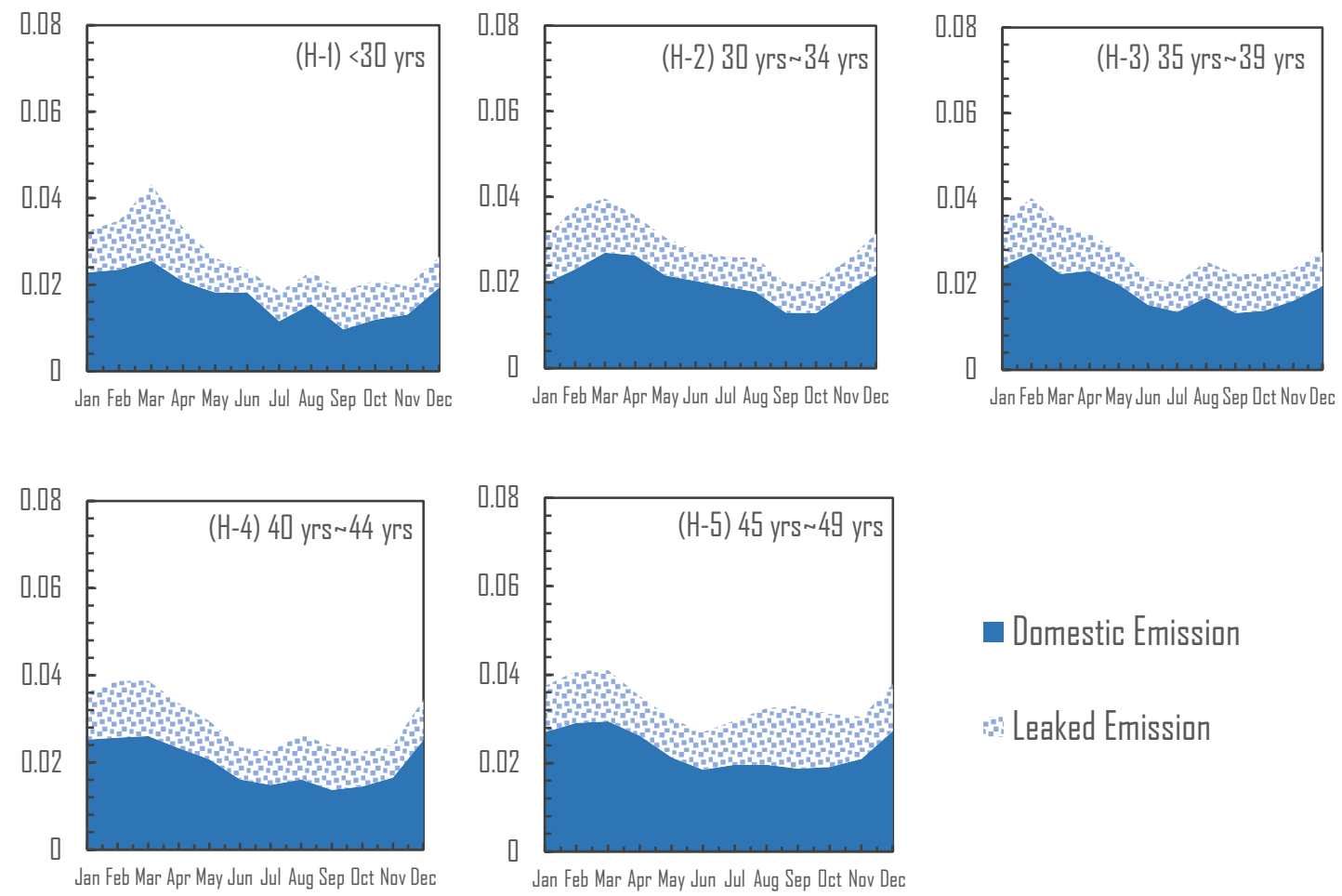

- Domestic Emission

: Leaked Emission

Fig. 4. Monthly domestic and leaked emissions by household type $\mathrm{HH}-a g e<50$ yrs. (tC per capita)
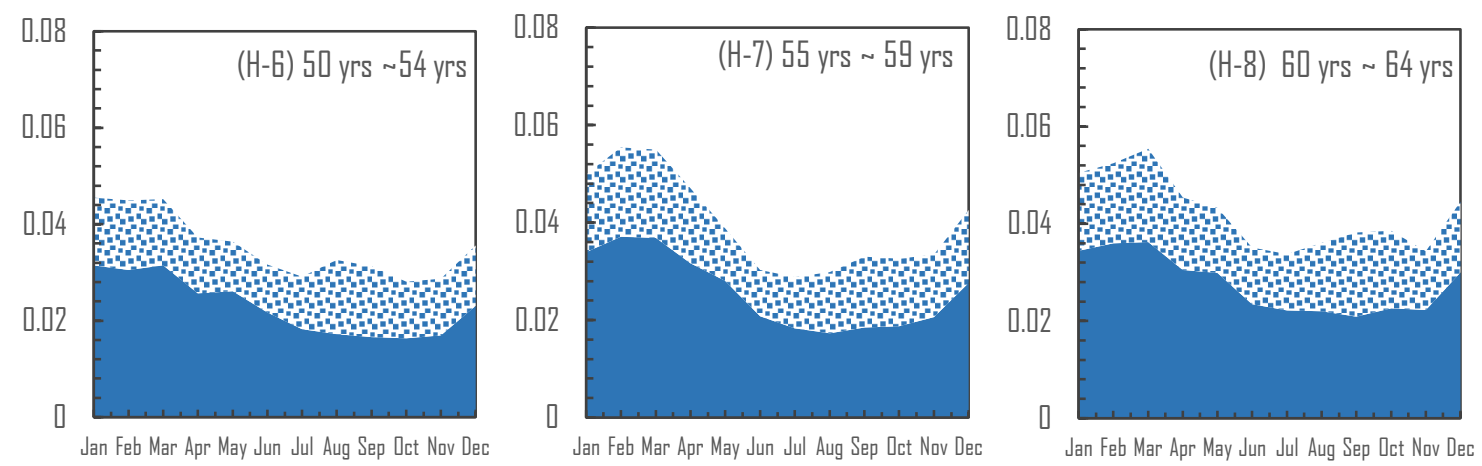

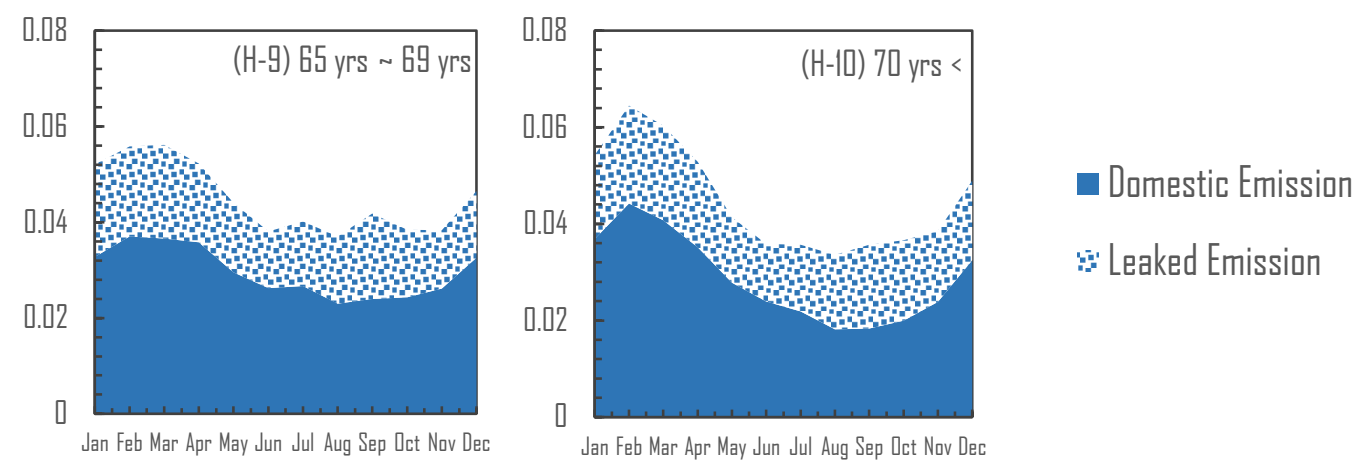

Fig. 5. Monthly domestic and leaked emissions for household type HH-Age $>50$ yrs. (tC per capita)

Fig. 5 shows monthly emissions levels for the five household groups in which the head-of-household age is relatively high (H-6 to H-10). Relative to the lower age group households featured in Fig. 4, the overall emissions levels here have increased markedly. Here again, overall household emissions show an upward trend as household age increases. The same is true for the two emissions componentsdomestic and leaked emissions. The per capita emissions of the households shown in Fig. 5 all have a clear emissions peak in February and March, similar to the situation described in Fig. 4. The average emissions when all household types are included are highest from January to April (January: 0.0414 tC per capita; February: 0.0465 tC per capita; March: 0.0469 tC per capita; April: 0.0404 tC per capita) and lowest in July (0.0285 tC per capita). Over the one-year period of the study, the highest emissions levels were found in the older household groups: H-8 (0.0423 tC/capita/month), H-9 (0.0451 tC/capita/month) and H-10 (0.0449 tC/capita/month).

The domestic emissions distribution shows higher domestic emissions levels for groups H-7 to H-10, which again indicates that older households produce greater emissions per capita. Moreover, leaked emissions were higher for these older households. The distribution also shows that as age increases, per capita residential emissions increase irrespective of source, and that household emissions are greatest in the cold seasons (i.e., from November to March). This finding reinforces the notion that aging impacts month-by-month household emissions responsibility. The peaks of leaked emission re found to be February and August. And the older household generated much more leaked emission the younger household. Therefore, the current emission responsibility of the older household is underestimated. 


\subsection{Monthly fuel-specific carbon emissions for ten HH-age-based household types}
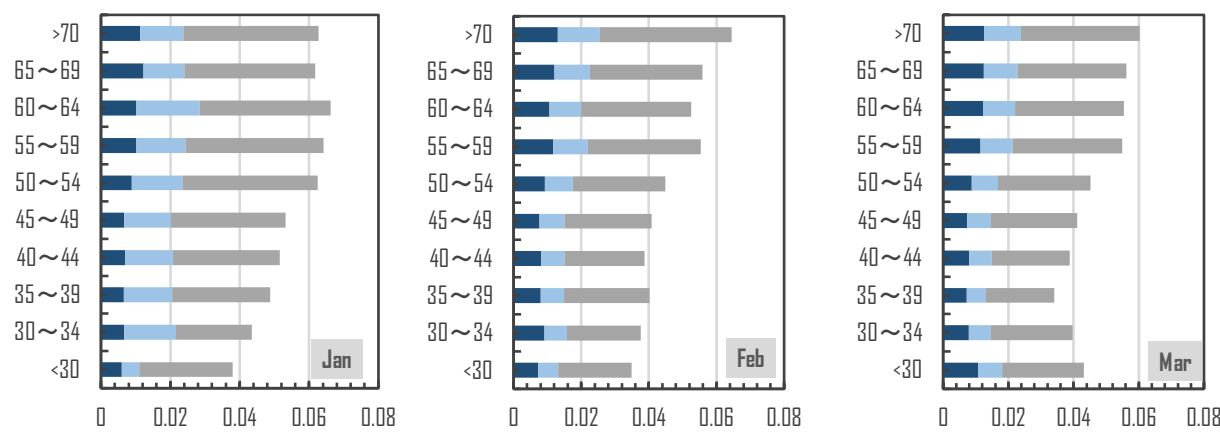

- Cal

- Crude Di
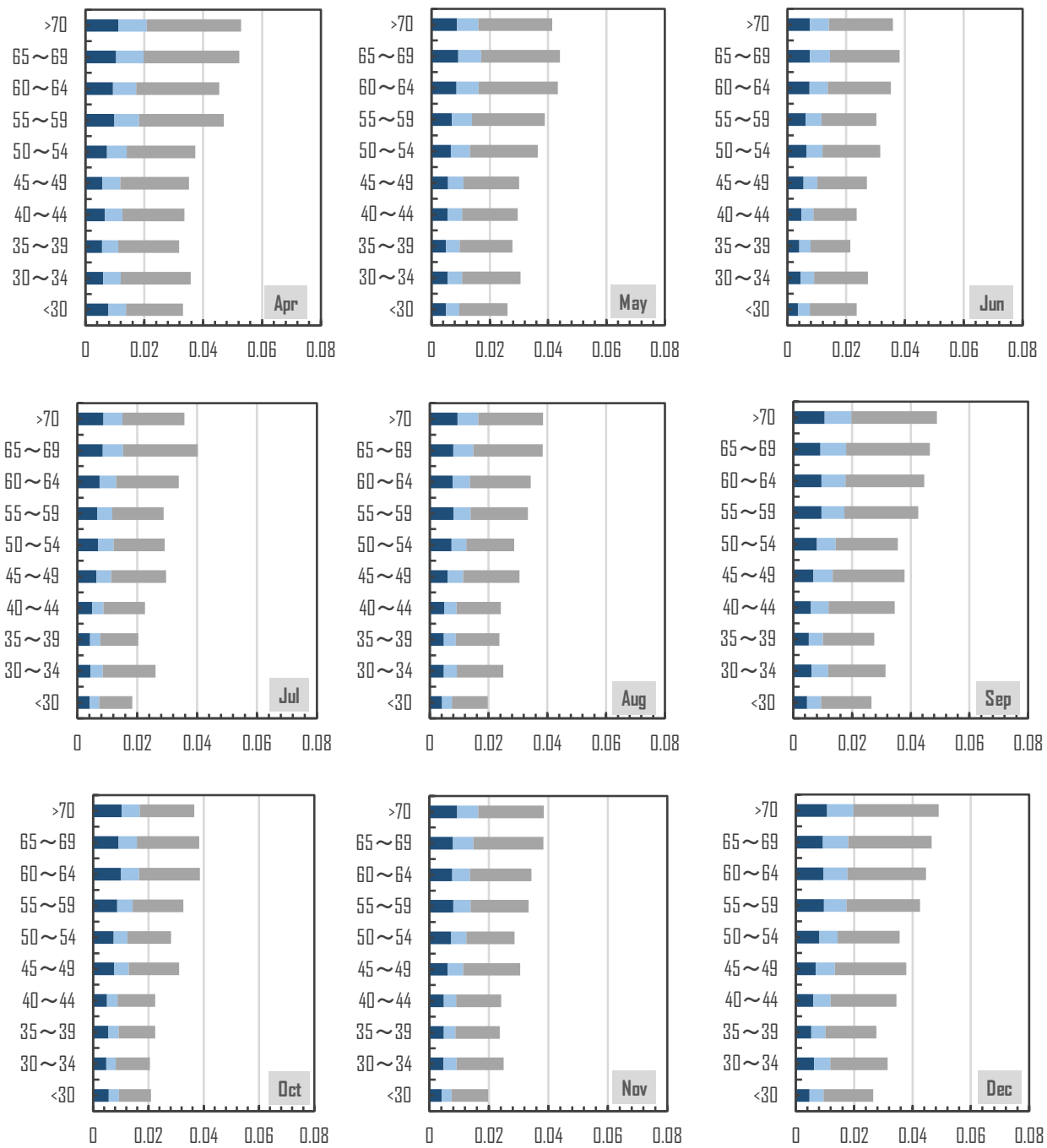

Fig 6: HH-Age group monthly emissions (Unit: tC per capita)

Fig. 6 shows the carbon emissions of our ten HH-Age groups, broken down by fuel type. Such information provides a highly useful basis for future structure upgrades and optimization. The largest 
emissions component here is clearly natural gas-generated emissions. However, based on seasonal variation and household type, the emissions structure changes in terms of both volume and composition. Compared to the natural gas-generated emissions, coal- and crude oil-generated emissions remain relatively stable across household types. The lowest natural gas emissions are found in group $\mathrm{H}-1(0.0163 \mathrm{tC}$ per capita), while the highest are in group H-9 $(0.0271 \mathrm{tC}$ per capita). This suggests that the major cause of the unequal emissions distributions of the ten household types is natural-gas related emissions. In reality, natural gas is combusted mostly for bath and cooking. Notably, the highest emissions levels are observed around the colder months of February and March. It seems reasonable to believe that the higher emissions of older households can be explained by the tendencies of older persons to be more sensitive to cold weather and thus have a higher demand for heat and hot water.

\subsection{Monthly direct and indirect carbon emissions for ten HH-age-based household types}
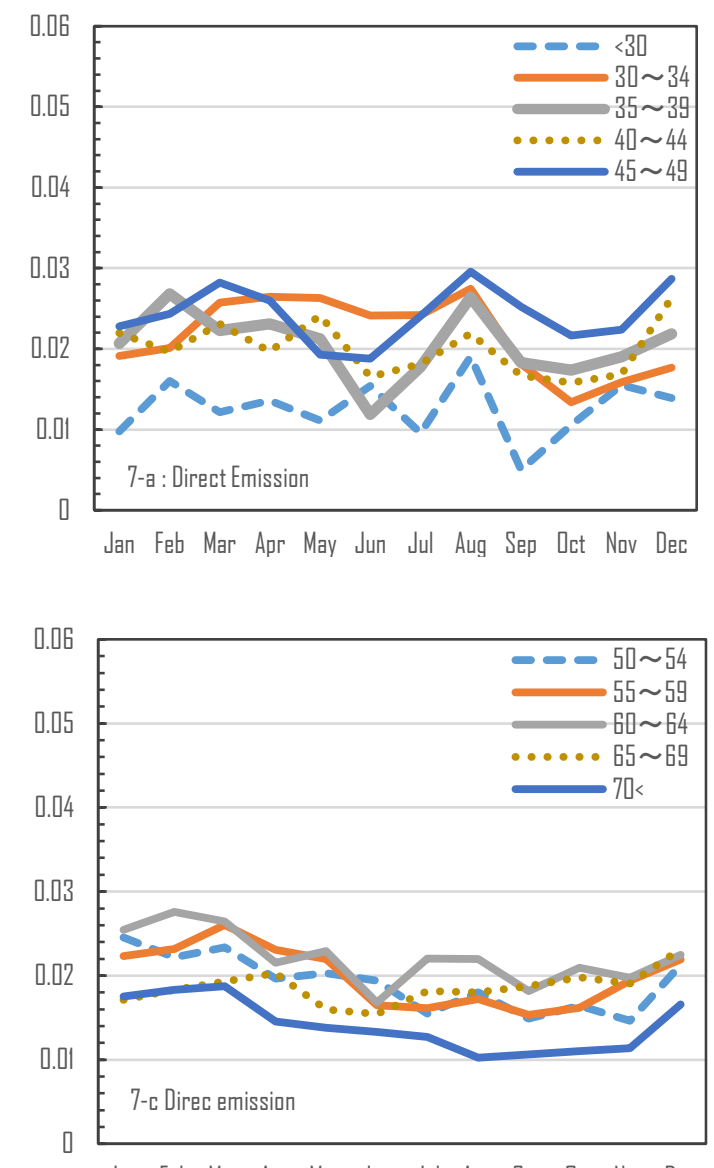

Jan Feb Mar Apr May Jun Jul Aụ Sep Dct Nov Dec
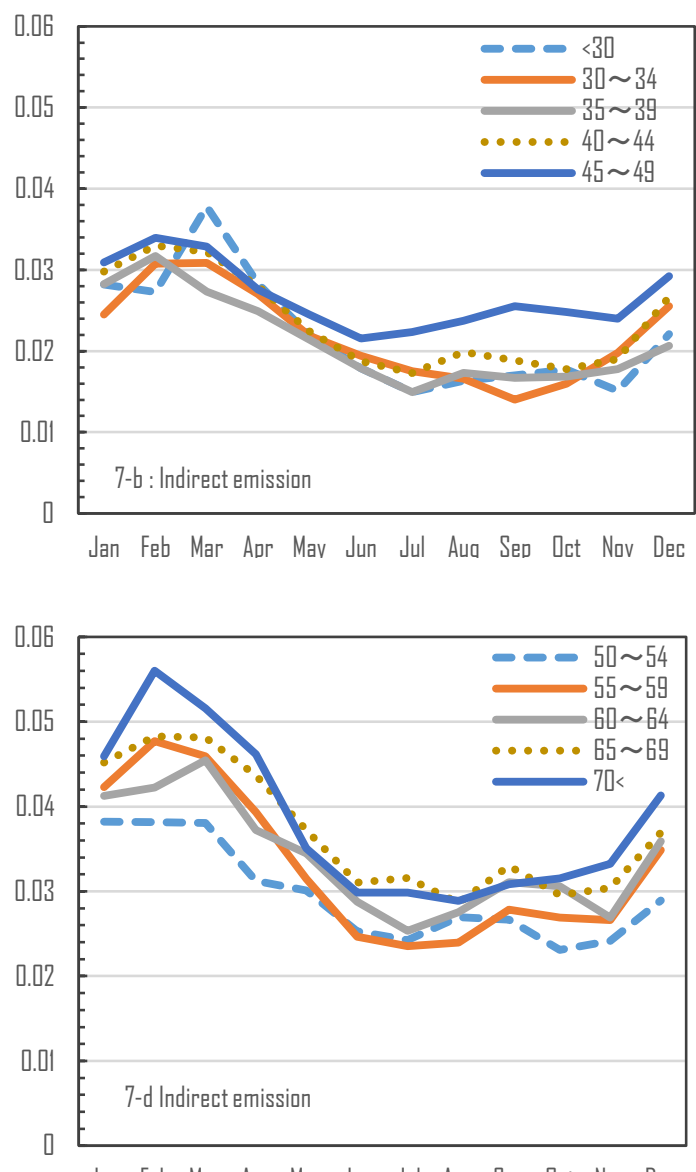

Jan Feb Mar Apr May Jun Jul Aug Sep Det Nav Dec 
Fig 7: Household age group emissions by month (Unit: tC per capita)

Fig. 7 provides another perspective on month-specific energy-related emissions, focusing on direct and indirect emissions. The intent is to highlight the emissions released in response to household demand rather than merely through direct consumption. Differentiating direct and indirect emissions, as defined in our introduction to system boundaries, also allows us to assess the bias associated with simply calculating the emissions released directly by households. The indirect emissions shown here are based on our input-output model and the regional inter-industrial correlations revealed. Generally speaking, indirect emissions have largely surpassed direct emissions for the area under study, which means that reporting only the emissions produced from the direct combustion of fuels by residents provides a wholly inadequate picture of total household emissions. Energy generation and the energy supply chain account for far more carbon emissions than the emissions associated with direct residential combustion.

The four charts in Fig. 7 highlight differences in the direct and indirect emissions of the younger versus older household groups. (The younger household groups are featured in 7-a and 7-b; the older groups are shown in 7-c and 7-d.) As presented here, direct emissions generally tend to fluctuate less significantly than indirect emissions, which means the seasonality of the indirect emission is more obvious than the indirect emission. Especially in Fig. 7-d, the H-8 group (HH-Age $>70$ yrs.) shows a steep drop from February to August in indirect emission. In contrast to the obvious indirect emissions fluctuations shown by Fig.7-b, direct emissions show a comparatively stable tendency, especially to the older groups. The obvious difference found from emission type and household younger and older group may indicate the future Japan's low-carbon household policy should fully consider the generation difference as well as seasonality. The steep increase of emission in cold season demands corresponding reduction measurement.

\subsection{Monthly residential carbon emissions by energy consumption item}

Fig. 9 and Fig. 10 show the emissions distribution by household consumption items, information that bears directly on the promotion of low-carbon household consumption habits. Based on the system boundary defined for the study, household consumption items are divided according to energy use into five categories: sewage, electricity, gasoline, gas, and other heating and lighting. Notably, kerosene is included as an "other heating and lighting" item. These household consumption items cover a majority 
of monthly household energy consumption.

Fig. 9 shows the monthly emissions distributions for groups $\mathrm{H}-1$ to $\mathrm{H}-4$, households that are comparatively young; the older households (groups H-5 to H-10) are featured in Fig. 10. The red dotted line shows the monthly emissions average for each specific group over the course of one year; the blue dotted line indicates the overall average emissions level for all months and all groups. In Fig. 9 , all the red dotted lines are below the blue dotted lines, indicating that the emissions level of the subject group is low relative to the overall average of the ten groups. Within each household group, the highest emissions are all found in February or March, while the lowest emissions levels are in the months from June to November. Gas was responsible for the highest emissions level among the five consumption items, followed by electricity. Gas is primarily used for cooking and bathing, with higher emissions in the colder seasons in the area under study. In another of our findings, the level of emissions generated by gasoline consumption is particularly high in group $\mathrm{H}-3$ (i.e., households in which the age of the head-of-household is between 30 and 34 years) The highest gasoline-related emissions for all the household types are in August, reflecting the likelihood that summer vacations encourage household members to drive more.

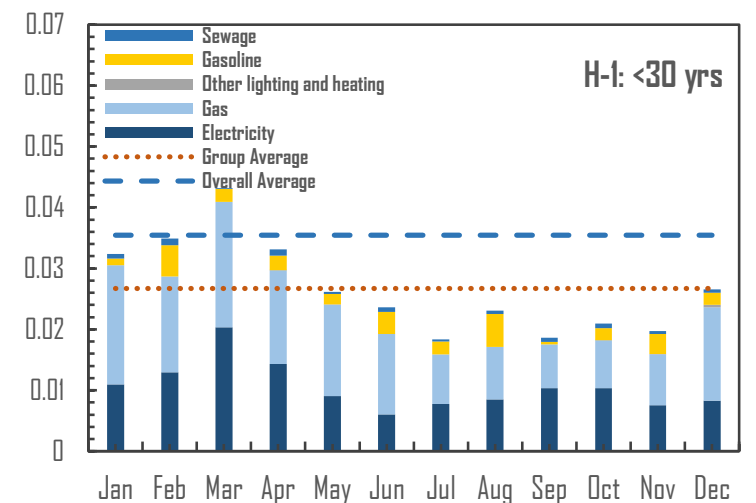

Jan Feb Mar Арг May Jun Jul Aug Sep Oct Nav Dec

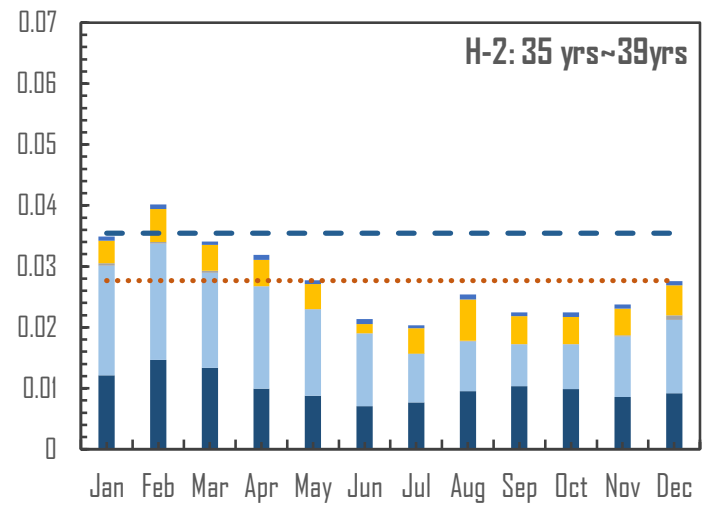

Jan Feb Mar Apr May Jun Jul Aug Sep Oct Nav Dec 

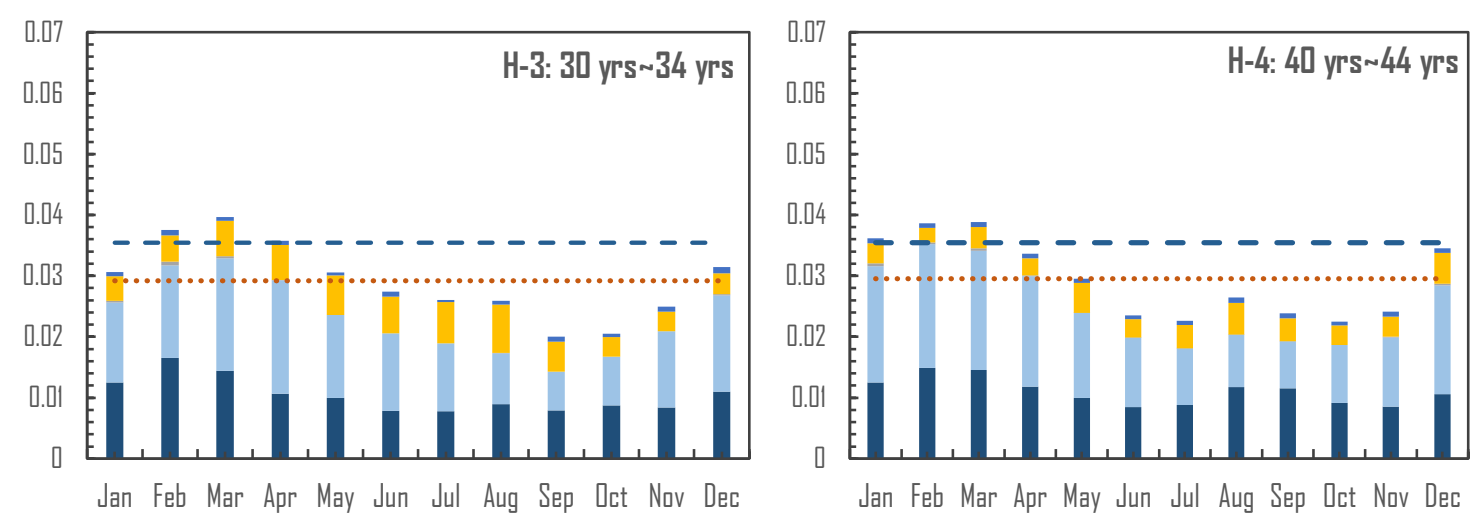

Fig 9: Monthly residential carbon emissions by energy consumption item (Groups H-1 to H-4)

As mentioned above, Fig. 10 shows the monthly distribution of emissions by household consumption items for groups H-5 to H-10. The households featured here are older than those represented in Fig. 9. Notice that, beginning with group H-7, the red dotted line (indicating the group average for the year) in the Fig. 10 charts is above the blue dotted line (indicating the average for all groups over the studied one-year period) and that the gap between the two lines grows larger as the age of the group increases. Moreover, the monthly emissions levels from December to March increase significantly, primarily due to gas consumption. These findings suggest that as households grow older, the emissions per household member increase substantially, mainly due to increases in electricity and gas consumption. Significantly, the structure of household energy consumption varies not only according to household but also according to season. Moreover, household emissions from August to October are mostly the result of residential electricity consumption, while gas combustion plays the major role in the other months.

Fig. 10 also reveals that households in which the head-of-household age is between 60 and 69 years show comparatively high emissions levels for gasoline, implying that this group drives more than the other household groups. However, when the household age increases to 70 years and above, it appears that household members prefer to stay at home, consuming more electricity and gas and driving less. To conclude, the emissions variations shown here suggest that changes in household needs and emissions are represented in monthly differences, an important point for the formulation of effective, customized low-carbon policies in the future. 


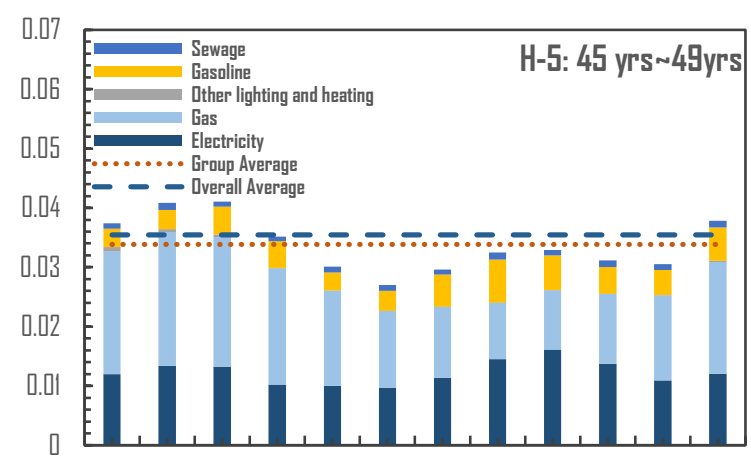

Jan Feb Mar Apr May Jun Jul Aug Sep Oct Nov Dec

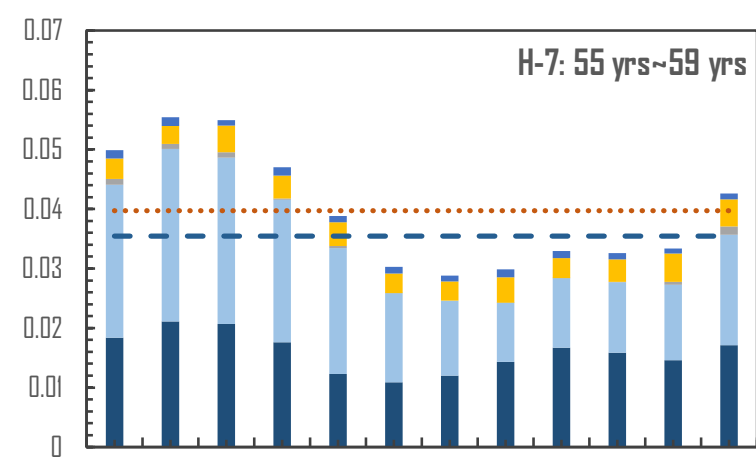

Jan Feb Mar Apr May Jun Jul Aug Sep Oct Nov Dec

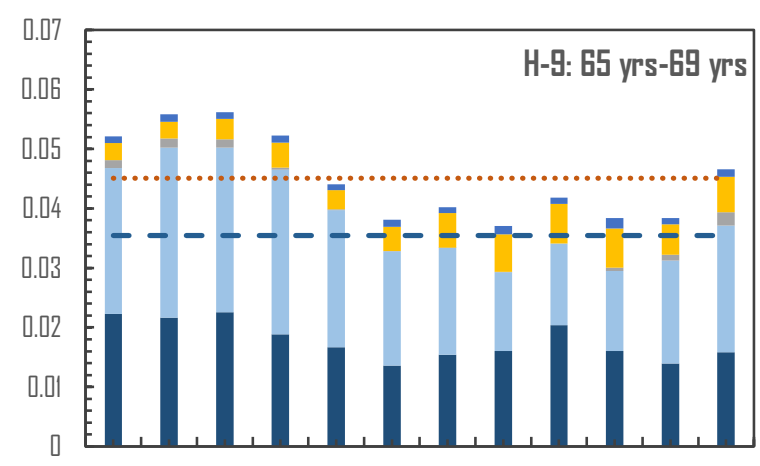

Jan Feb Mar Apr May Jun Jul Aug Sep Oct Nov Dec

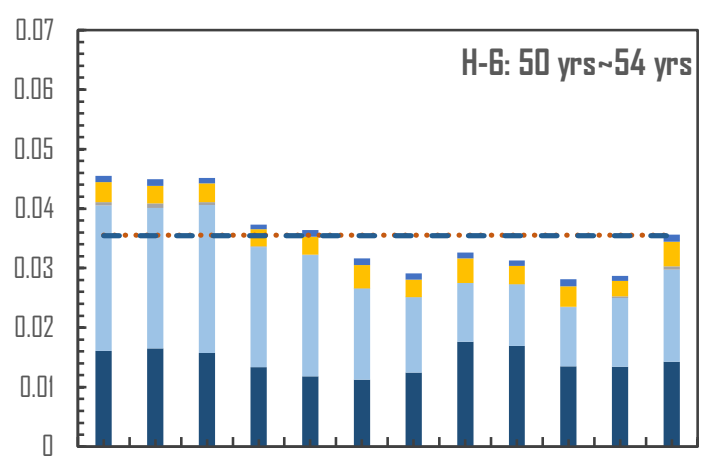

Jan Feb Mar Apr May Jun Jul Aug Sep Oct Nav Dec
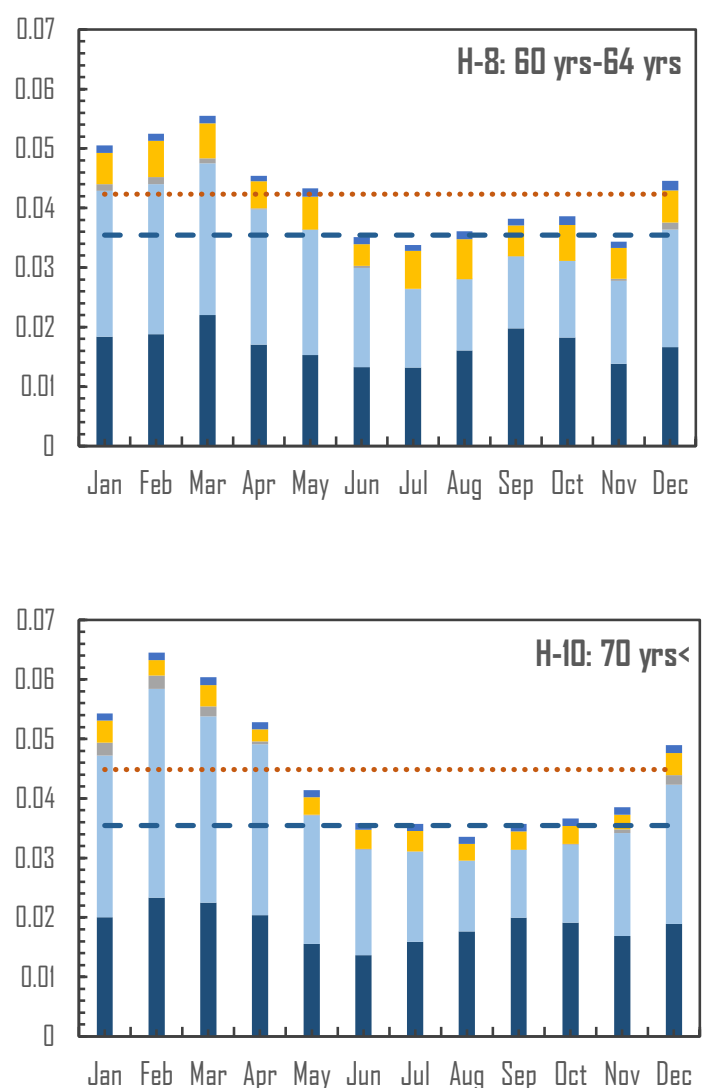

Fig 10: Monthly residential carbon emissions by energy consumption item (Groups H-5 to H-10)

\section{Conclusions and policy implications}

Households are the major driver of an economy, triggering a series of economic actives along the supply chain through a collection of consumption behaviors. City residential emissions are strongly 
influenced by household lifestyle, which itself is impacted by a variety of factors - physical, social and economic - that affect resource use and the associated carbon emissions. A better understanding of the household emissions structure will enable us to effectively allocate household emissions based on knowable household characteristics. The use of survey data on monthly household expenditures provides the foundation for a bottom-up approach to determining household consumption patterns and provides a basis for measuring carbon emissions from the consumption side. The input-output model enables the quantification of embodied emission. The present study assesses city-scale household energy-related emissions by emission sources, emission types, fuel types, and consumption items. Results indicate that household age has a measurable impact on household per capita emissions and on month-to-month differences in emissions levels.

The study's main conclusions can be summarized as follows:

(1) Household emissions vary by month. Based on our household consumption data, maximum emissions levels occur in February and March, while emissions levels from June to November are relatively low. For the residential sector in the area under study, this means that low temperature months produce high emissions, while the warmer months produce lower emissions. Furthermore, the difference (or gap) in monthly emissions levels among the ten age-based household groups varies from month to month, which means that the extent to which households are affected by seasonal factors differs among the various household groups. Such a finding further illustrates the need for a more detailed study of city-scale household emissions.

(2) Our multi-regional input-output model allowed us to separate embodied emissions into two sourcerelated classifications: domestic emissions and leaked emissions. Results show that both domestic and leaked emissions reach comparatively high levels in February and March, but remain relatively low from July to September. Moreover, we found that as household age increases, emissions of both types also increase.

(3) When emissions by household group and month are further subdivided by fuel type - in this case, coal, crude oil and natural gas - natural gas is shown to play the major role in each household group, irrespective of month. Such a result is not particularly surprising. Natural gas is combusted by residents in the study area for cooking, bathing, and electricity. Thermal power generation for the city of Tokyo is primarily produced along Tokyo Bay and relies heavily on liquefied natural gas. The Shinagawa Power Plant, which began operations in August 2003, is the largest of these power-generating facilities; its major fuel is city gas (i.e., manufactured town gas). 
(4) Emissions in older households are comparatively high. Although this may not be immediately apparent, it becomes more evident when emissions are assigned on a per-household-member (i.e., a per capita) basis. While middle-aged households are shown to produce higher emissions than other household groups, these middle-aged households also tend to be larger. (Fig. 11 shows the average household size for the ten household groups included in the study.) Thus, even though older households may produce lower emissions when considered on a per-household basis, they tend to produce more emissions on a per-household-resident basis, indicating that energy consumption efficiency is lower in older households. Using household units to evaluate residential emissions thus has its limitations if one wishes to quantify energy consumption efficiency. The low energy efficiency of older households identified in this study should be an important factor in setting priorities for future emissions reduction policies.

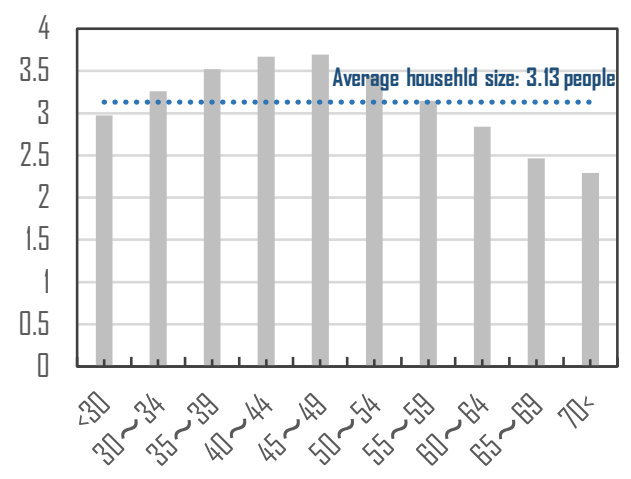

Fig 11: Average household member and its distribution of Tokyo in 2011 (Unit: People)

(5) Direct emissions, which are associated with energy consumed directly by the household (such as burning natural gas to cook or heat water), account for a smaller proportion of total household emissions than do indirect emissions, which have their source in the upstream supply chain. Direct emissions also show less seasonality. Importantly, older households have far greater levels of direct emissions than younger households. Overall, the amount of indirect emissions is much higher than the amount of direct emission mainly due to the generation of electricity and the production and transportation of natural gas. To properly evaluate residential emissions responsibility, consumptionside accounting has the ability to capture embodied emissions produced in other industries, either domestically or externally.

(6) Assessing household emissions based on consumption items, which provides an indicator of household consumption behaviours with respect to energy needs, reveals high emissions levels in older 
households during the cold seasons; this is less true in younger households. The largest contributor is gas combustion, which entails both direct and indirect emissions. As a household ages, per capita household energy consumption increases due to an increase in heating demand. Thus, any future emissions reduction policy should encourage aging households in Tokyo to adopt more efficient heating systems. Improving the insulation of housing materials, especially windows and doors, and optimizing residential heating systems have great potential to reduce carbon emissions, particularly in older households. Given the irreversible trend of Japan's aging population, promoting more efficient consumption behaviours in aging households can play a significant role in overall climate change mitigation.

Long-term energy targets have been set by Japan and three major energy challenges are pointed out, including the self-sufficiency, electricity price and the greenhouse gas issue. To respond to these challenges, two pillars are proposed to overcome the energy challenge and realize a stable energy supply: energy conservation and balance energy supply. To promote energy conservation promotion, households sector is expected to take the major responsibility to complete reduction target. Current days, several tangible approaches are conducting in Japan's household sector, such as building and renovating household based on new energy conservation standards as well as replacing equipment with high-efficiency consumer electronics and water heater. However, the demand-side information is vital for if these conservation measurements can be conducted in reality. Therefore, the detail information of consumption feature and adequate emission allowance estimation is in need. This study provides the household preference on energy consumption by diving them into different age-based groups. The output can further be applied to improve the efficiency of infrastructure and equipment, especially to the inefficient consumption pattern of the older household in cold seasons. And the experience of Tokyo also can be referred as setting reduction priorities of other mega cites worldwide.

\section{Limitations and future perspectives}

Beginning with consumption-based accounting method, this study investigated residential carbon emissions based on energy type, emission type, emission source and consumption items. Emission inequality are discussed both among ten household group and month. However, there are at least three limitations to our study: (1) the system boundary in the study does not cover all indirect household emissions. While the current study examines household emissions based on energy needs, other demands, including the demand for food or accommodation, have not been considered; (2) the current study divided 
households into ten groups based on head-of-household age rather than by average household age. This may have produced a bias in our household group classification scheme. However, to our knowledge, there is no comprehensive database detailing monthly household expenditures by average household age available for the city of Tokyo. Given such a database, better analysis may be possible. (3) beside of household age, emission inequality can be dissected based on other standards, such as household income and living environment.

As for future research, our work can be further enriched by investigating the relationship between other household characteristics and household emissions. Moreover, while our attention has been focused exclusively on $\mathrm{CO}_{2}$ emissions, examining other air pollutants, such as PM 2.5 and nitrogen dioxide, is an appealing next step. Finally, applying the method used in our Tokyo study to other cities and discovering common/universal features of city-level household energy consumption and emissions structure would be highly desirable.

\section{Conflicts of interest: None}

\section{Acknowledgement}

This work was supported by the Center for Low Carbon Society Strategy (LCS), Japan Science and Technology Agency (JST).

Büchs, M., \& Schnepf, S. V. (2013). Who emits most? Associations between socio-economic factors and UK households' home energy, transport, indirect and total $\mathrm{CO} 2$ emissions. Ecological Economics, 90, 114-123. doi: 10.1016/j.ecolecon.2013.03.007

Chen, G., Hadjikakou, M., \& Wiedmann, T. (2017). Urban carbon transformations: unravelling spatial and inter-sectoral linkages for key city industries based on multi-region inputoutput analysis. Journal of Cleaner Production, 163, 224-240. doi: https://doi.org/10.1016/j.jclepro.2016.04.046

Froemelt, A., Dürrenmatt, D. J., \& Hellweg, S. (2018). Using Data Mining To Assess Environmental Impacts of Household Consumption Behaviors. Environ Sci Technol, 52(15), 8467-8478.

Joji, A., Miura, S., \& Yutaka, T. (1999). A study on the Characteristics of CO_2 emissions by City Class: Calculation of $\mathrm{CO}_{-} 2$ emissions based on the family consumption expenditure. Architectural Institute of Japan, 1999, 951-952. 
Lenzen, M. (1998). Primary energy and greenhouse gases embodied in Australian final consumption: an input-output analysis. Energy Policy, 26(6), 495-506.

Lenzen, M., Murray, S. A., Korte, B., \& Dey, C. J. (2003). Environmental impact assessment including indirect effects-a case study using input-output analysis. Environmental Impact Assessment Review, 23(3), 263-282. doi: 10.1016/s0195-9255(02)00104-x

Lenzen, M., Pade, L.-L., \& Munksgaard, J. (2010). CO2Multipliers in Multi-region Input-Output Models. Economic Systems Research, 16(4), 391-412. doi: 10.1080/0953531042000304272

Lenzen, M., Wier, M., Cohen, C., Hayami, H., Pachauri, S., \& Schaeffer, R. (2006). A comparative multivariate analysis of household energy requirements in Australia, Brazil, Denmark, India and Japan. Energy, 31(2-3), 181-207. doi: 10.1016/j.energy.2005.01.009

Lenzen, M., Wood, R., \& Wiedmann, T. (2010). Uncertainty analysis for multi-region input-output models-a case study of the UK's carbon footprint. Economic Systems Research, 22(1), 4363.

Long, Y., Dong, L., Yoshida, Y., \& Li, Z. (2018). Evaluation of energy-related household carbon footprints in metropolitan areas of Japan. Ecological Modelling, 377, 16-25. doi: https://doi.org/10.1016/j.ecolmodel.2018.03.008

Long, Y., \& Yoshida, Y. (2018). Quantifying city-scale emission responsibility based on input-output analysis - Insight from Tokyo, Japan. Applied Energy, 218, 349-360. doi: 10.1016/j.apenergy.2018.02.167

Long, Y., Yoshida, Y., \& Dong, L. (2017). Exploring the indirect household carbon emissions by source: Analysis on 49 Japanese cities. Journal of Cleaner Production, 167, 571-581. doi: 10.1016/j.jclepro.2017.08.159

Long, Y., Yoshida, Y., Zhang, R., Sun, L., \& Dou, Y. (2018). Policy implications from revealing consumption-based carbon footprint of major economic sectors in Japan. Energy Policy, 119, 339-348. doi: https://doi.org/10.1016/j.enpol.2018.04.052

Mach, R., Weinzettel, J., \& Ščasný, M. (2018). Environmental Impact of Consumption by Czech Households: Hybrid Input-Output Analysis Linked to Household Consumption Data. Ecological Economics, 149, 62-73. doi: https://doi.org/10.1016/j.ecolecon.2018.02.015

Nansai, K., Kondo, Y., Kagawa, S., Suh, S., Nakajima, K., Inaba, R., \& Tohno, S. (2012). Estimates of embodied global energy and air-emission intensities of Japanese products for building a Japanese input-output life cycle assessment database with a global system boundary. Environ Sci Technol, 46(16), 9146-9154. doi: 10.1021/es2043257

Perobelli, F. S., Faria, W. R., \& Vale, V. d. A. (2015). The increase in Brazilian household income and its impact on $\mathrm{CO} 2$ emissions: Evidence for 2003 and 2009 from input-output tables. 
Energy Economics, 52, 228-239. doi: https://doi.org/10.1016/j.eneco.2015.10.007

Ramaswami, A., Chavez, A., Ewing-Thiel, J., \& Reeve, K. E. (2011). Two approaches to greenhouse gas emissions foot-printing at the city scale: ACS Publications.

Reinders, A. H. M. E., Vringer, K., \& Blok, K. (2003). The direct and indirect energy requirement of households in the European Union. Energy Policy 31(2), 139-153.

Shigetomi, Y., Matsumoto, K. i., Ogawa, Y., Shiraki, H., Yamamoto, Y., Ochi, Y., \& Ehara, T. (2018). Driving forces underlying sub-national carbon dioxide emissions within the household sector and implications for the Paris Agreement targets in Japan. Applied Energy, 228, 2321-2332. doi: https://doi.org/10.1016/j.apenergy.2018.07.057

Shigetomi, Y., Nansai, K., Kagawa, S., \& Tohno, S. (2014). Changes in the carbon footprint of Japanese households in an aging society. Environ Sci Technol, 48(11), 6069-6080. doi: 10.1021/es404939d

Singh, S., \& Kennedy, C. (2015). Estimating future energy use and CO(2) emissions of the world's cities. Environ Pollut, 203, 271-278. doi: 10.1016/j.envpol.2015.03.039

Wang, Z., Liu, W., \& Yin, J. (2014). Driving forces of indirect carbon emissions from household consumption in China: an input-output decomposition analysis. Natural Hazards, 75(S2), 257-272. doi: 10.1007/s11069-014-1114-7

Wiedenhofer, D., Guan, D., Liu, Z., Meng, J., Zhang, N., \& Wei, Y.-M. (2017). Unequal household carbon footprints in China. Nature Climate Change, 7(1), 75.

Zhang, H., Liang, Y., Liao, Q., Wu, M., \& Yan, X. (2017). A hybrid computational approach for detailed scheduling of products in a pipeline with multiple pump stations. Energy, 119, 612-628.

Zhang, H., Liang, Y., Liao, Q., Yan, X., Shen, Y., \& Zhao, Y. (2017). A three-stage stochastic programming method for LNG supply system infrastructure development and inventory routing in demanding countries. Energy, 133, 424-442.

Zhang, H., Song, X., Xia, T., Yuan, M., Fan, Z., Shibasaki, R., \& Liang, Y. (2018). Battery electric vehicles in Japan: Human mobile behavior based adoption potential analysis and policy target response. Applied Energy, 220, 527-535.

Zhang, J., Yu, B., Cai, J., \& Wei, Y.-M. (2017). Impacts of household income change on CO2 emissions: An empirical analysis of China. Journal of Cleaner Production, 157, 190-200.

Zhang, Y.-J., Bian, X.-J., Tan, W., \& Song, J. (2015). The indirect energy consumption and CO2 emission caused by household consumption in China: an analysis based on the inputoutput method. Journal of Cleaner Production. doi: 10.1016/j.jclepro.2015.08.044

Zhu, Q., Peng, X., \& Wu, K. (2012). Calculation and decomposition of indirect carbon emissions from residential consumption in China based on the input-output model. Energy Policy, 48, 618-626. doi: 10.1016/j.enpol.2012.05.068 
